\title{
MIGRAÇÃO DE VALOR NA INDÚSTRIA FARMACÊUTICA ${ }^{1}$
}

\section{VALUE MIGRATION IN THE PHARMACEUTICAL INDUSTRY}

\author{
Alexandre Fillietaz ${ }^{2}$ \\ Sergio Feliciano Crispim ${ }^{3}$
}

\begin{abstract}
RESUMO: Esta pesquisa buscou identificar os principais fatores de competitividade que têm influenciado a migração de valor de mercado entre empresas do setor farmacêutico internacional que têm capital aberto na Bolsa de Valores de Nova Iorque. A análise apoiou-se nos dados coletados a partir dos relatórios anuais disponibilizados por quarenta e sete empresas, e que fundamentaram a construção de uma série histórica de 1998 a 2007 na qual relacionamos a evolução das vendas ao valor das empresas. O valor relativo das empresas foi utilizado como um indicador "proxy" da competitividade, e a evolução das curvas de valor possibilitaram identificar a migração dos investimentos, ou do valor, entre diferentes empresas concorrentes. Os principais indicadores utilizados para explicar as curvas de crescimento foram o investimento em pesquisa e desenvolvimento (P\&D), o portfólio de produtos em desenvolvimento e lançados no mercado, e as alianças estratégicas. Os resultados preliminares obtidos na investigação de natureza exploratória indicam que embora o setor farmacêutico em geral apresente altos índices de crescimento e lucratividade, as empresas mais bem avaliadas, ou com capacidade de criação de valor acima da média, foram as que apresentaram estratégias fundamentadas principalmente nos denominados ativos intelectuais, ou intangíveis. De forma geral as empresas que mais atraíram o capital dos investidores, e apresentaram maior crescimento da capitalização de mercado, foram empresas de menor porte, caracterizadas por maior flexibilidade e por modelos de negócios mais inovadores. Estas empresas, embora relativamente pequenas quando comparadas aos grandes laboratórios multiespecialistas, concentraram-se na pesquisa e desenvolvimento em algumas classes terapêuticas nas quais se tornaram relativamente grandes. Como resultado desta estratégia focada, elas conseguiram obter indicadores de investimento em $\mathrm{P} \& \mathrm{D}$, que são importantes fatores de competitividade na indústria farmacêutica, relativamente elevados, além de terem sido objeto de parcerias estratégicas com grandes laboratórios que delas dependem para se manterem na fronteira do desenvolvimento.
\end{abstract}

PALAVRAS-CHAVE: Indústria farmacêutica. Criação e migração de valor. Ativos intangíveis

ABSTRACT: This research aimed to identify the main factors of competitiveness that have influenced the migration of market value among pharmaceuticals international companies with open capital on the New York Stock Exchange. The analysis was supported by data collected from the annual reports made available by forty seven companies, and which motivated the construction of a historical series from 1998 to 2007 in which the sales evolution was related to the value of the undertakings. The relative value of companies was used as an indicator "proxy" of competitiveness, and the evolution of the curves of value made the identification of investments or values migration among different competitors possible. The main indicators used to explain the growth curves were the investment in research and development (R\&D), which is an important factor of competitiveness in the pharmaceutical industry, the portfolio of products in development and launched on the market, and the strategic alliances. The preliminary results obtained in the exploratory nature investigation indicated that although the pharmaceutical sector usually presents high rates of growth and profitability, companies better evaluated or with capacity to create value above the average were the ones that presented strategies based on intangible assets. In general companies that attracted the capital of investors, and also presented higher growth of market capitalization, were smaller companies, characterized by greater flexibility more innovative and business models. Although relatively small when compared to large laboratories multispecialists, these companies concentrated the research and development in some therapeutic classes so that they have become relatively big in them. As a result of this focused strategy, they succeeded in obtaining indicators of investment in $R \& D$, which are important factors of competitiveness in pharmaceutical industry: relatively high they have been the object of strategic partnerships with major laboratories that depend on them to remain at the border of development.

KEYWORDS: Pharmaceutical industry. Value creation and migration. Intangible assets.

\footnotetext{
${ }^{1}$ Artigo Recebido em 11.02.2009. Revisado por pares em 24.03.2010. Recomendado em 26.04.2010 por Leomar dos Santos Editor. Publicado em 04.04.2011.

Organização Responsável pelo periódico: Universidade regional de Blumenau - FURB - www.furb.br/rn
}

\footnotetext{
${ }^{2}$ Universidade Municipal de São Caetano do Sul - UCS - afillietaz@gmail.com

${ }^{3}$ Universidade Municipal de São Caetano do Sul - UCS - scripim@uol.com.br
} 


\section{INTRODUÇÃO}

As empresas farmacêuticas acreditam que um dos principais fatores-chave de sucesso do segmento é o contínuo desenvolvimento do conhecimento orientado para a síntese de novas moléculas. A proteção dessas moléculas, por meio de um processo de reconhecimento da patente, gera ativos intangíveis que garantem a manutenção da competitividade dos laboratórios farmacêuticos. As altas taxas de retorno sobre os investimentos de uma substância ativa que venha a tornar-se um medicamento de sucesso vêm se mostrando como o melhor caminho para a criação de valor junto aos acionistas (ANDRADE \& LISBOA, 2000).

No quesito pesquisa e desenvolvimento, a comparação da indústria farmacêutica aos demais segmentos industriais leva à conclusão que, enquanto outros setores investem em média 4\% do faturamento em P\&D (Pesquisa e Desenvolvimento), na indústria farmacêutica, os laboratórios de produtos com necessidade de prescrição médica, investem em média 21,2\% do faturamento na pesquisa e na formulação de novos produtos. Apesar da maior efetividade destes medicamentos, seu desenvolvimento mobiliza um alto volume de recursos não subsidiados, o que resulta em tratamentos acessíveis apenas a uma pequena parcela da população (FAGAN, 1998). Ainda segundo Fagan (1998), a pesquisa e o desenvolvimento de novas drogas levam em média 12 anos e o investimento pode chegar a 350 milhões de dólares que, de acordo com Rupprecht (1999), representam em média 20,3\% da receita das empresas.

O valor de uma empresa revela-se como um critério relevante de avaliação de desempenho principalmente a partir das décadas de 1980 e 1990, quando surgiu a crença de que os administradores que se concentram na construção de valor para os acionistas criam, paralelamente, empresas mais saudáveis do que aqueles que não o fazem. Outro pensamento que surge neste contexto é o de que as empresas mais saudáveis contribuem para a construção de economias mais sólidas e têm maiores chances de manter competitividade superior frente aos concorrentes (COPELAND et al, 2002). Neste contexto, a busca da criação de valor no setor farmacêutico a partir da década de 90 estimulou processos de fusões, aquisições e reestruturações influenciadas por uma série de fatores de natureza macro, como: mudanças tecnológicas, desregulamentação dos mercados, privatizações, globalização financeira e dos mercados e a alta liquidez de bancos e das grandes corporações combinada com a valorização dos mercados acionários. Do ponto de vista microeconômico, as operações de fusões e de aquisições são muito influenciadas pela necessidade e busca da redução de custos relacionados a ganhos de economia de escala e escopo, além de uma maior participação nos mercados em um contexto de acirramento da competição internacional (HITT et al, 2005).

O novo cenário competitivo enfrentado pelos administradores do setor farmacêutico exige das empresas uma melhor relação com o mercado financeiro e com os acionistas, que passam a influenciar significativamente as suas decisões. Nesse sentido, foi definido o seguinte objetivo geral para a pesquisa realizada:

- Analisar a migração de valor entre as maiores empresas da indústria farmacêutica global com base em uma série histórica de receitas e valor de mercado no período de 1998 a 2007, e na identificação e revisão de alguns importantes fatores de competitividade. 


\section{REFERENCIAL CONCEITUAL}

\subsection{Os Ativos Intangíveis e a Competitividade da Indústria Farmacêutica}

Segundo Lev (2001) os ativos intangíveis são cada vez mais determinantes da competitividade de uma empresa, e neste sentido é fundamental compreender a importância dos ativos intangíveis e a sua diferença em relação aos tangíveis. Na visão contábil, ou tangível, os ativos são considerados bens e direitos de uma entidade, precificáveis em moeda e à disposição da administração para as operações presentes e geração de benefícios futuros, que são criados pela inovação, por práticas organizacionais e pelos recursos humanos, alguns ativos intangíveis que interagem com os ativos tangíveis na criação do valor corporativo e no crescimento econômico. Complementarmente, para Kayo (2002, p. 14) os ativos intangíveis podem ser definidos como a união da estrutura de conhecimentos, práticas e ações da empresa, as quais, interagindo com seus ativos tangíveis, contribuem para a construção do valor das organizações. Os ativos intangíveis podem ser descritos como ativos de natureza permanente, sem existência física, que são capazes de prover benefícios futuros à empresa que os controla.

Segundo Boulton et al (2001) a evolução e valorização das empresas estão relacionadas cada vez mais aos ativos intangíveis, ou ativos intelectuais. Os ativos tangíveis e os ativos financeiros têm produzido predominantemente retornos médios, ou abaixo da média, aos seus investidores. Os retornos acima da média e as posições competitivas dominantes são cada vez mais determinados pelos ativos intangíveis.

De acordo com Lev (2001), o aumento do interesse sobre os ativos intangíveis está relacionado à combinação de duas forças econômicas: o aumento da competição entre as empresas e a evolução da tecnologia da informação. Em um a ambiente competitivo caracterizado por mudanças cada vez mais rápidas e profundas um atributo fundamental para melhorar a competitividade das empresas é a flexibilidade, ou a capacidade de mudar rapidamente. Quanto maior a importância dos ativos intangíveis no portfólio de ativos das empresas, maior é sua capacidade para mudar rapidamente, que se tornou uma vantagem competitiva no mundo atual. Embora os ativos intangíveis sejam de difícil mensuração pelos métodos contábeis tradicionais, eles têm mostrado uma capacidade crescente para criar valor de mercado para as empresas de capital aberto, ao melhorarem as expectativas em relação aos resultados futuros e o valor presente do fluxo de caixa as estes resultados vinculado (SLYWOTZKY, 1997). Nesse contexto, a relevância dos ativos intangíveis é a característica que mais determina a competitividade dos laboratórios farmacêuticos na nova economia Alguns ativos intangíveis já são contabilizados, e um exemplo desta prática na indústria farmacêutica são os gastos necessários para o reconhecimento de patentes e para a pesquisa e desenvolvimento de novos produtos ou a melhoria de produtos já existentes. Estes ativos são registrados pelo seu custo histórico de maneira semelhante aos demais itens que compõem o ativo. Para Aversari Martins (2002), os investimentos para o desenvolvimento dos ativos intangíveis ficam alocados no ativo até o momento no qual as receitas são identificadas, para que após o confronto entre os investimentos e as receitas possa ser combinado a outros indicadores que permitam a avaliação do novo ativo intangível.

Uma séria consequência da falta do tratamento apropriado aos ativos intangíveis nãoadquiridos, como o próprio capital intelectual, poderá ser a dificuldade dos gestores perceberem que boa parte dos ativos intangíveis está relacionada a despesas já incorridas. 
Esse pensamento pode inibir os investimentos em ativos intangíveis, principalmente quando os administradores não estão conscientes da importância estratégica destes investimentos ou, por algum motivo, estiverem excessivamente preocupados com os resultados de curto prazo, como, por exemplo, o retorno por ação (LEV, 2000).

Segundo Lev (2000), a deficiência da informação disponível nos demonstrativos financeiros de uma empresa pode trazer sérias consequências, dentre as quais destacamos um maior custo do capital, principalmente em empresas muito intensivas em ativos de conhecimento, como é o caso da indústria farmacêutica, e uma subavaliação por investidores das ações de empresas intangível-intensivas, com destaque para as que ainda não alcançaram níveis significativos de lucratividade. Lev (2000) afirma ainda que, quando se trabalha com ativos intangíveis ou ativos do conhecimento, o valor pode ser construído ou destruído sem que seja necessário qualquer tipo de transação. Ele utiliza como exemplo a indústria farmacêutica, demonstrando que um medicamento, ao ser aprovado em testes clínicos, cria um valor enorme, embora não haja transação alguma.

\subsection{A Migração de Valor Entre as Concepções de Negócios}

A discussão quanto à importância do valor para os acionistas em relação a outras medidas de desempenho, como o nível de emprego, a sustentabilidade e a responsabilidade social, sempre existiram e continuam a existir, e o foco das discussões costuma ficar na relação conflituosa entre os interesses dos acionistas e dos outros stakeholders. No caso do mercado farmacêutico dos Estados Unidos, no aspecto jurídico e ideológico, o maior peso é dado ao fato de que os acionistas são os proprietários das empresas e que o conselho administrativo é eleito por eles para representá-los, e assim o objetivo das empresas é o de maximizar o valor para os acionistas (COPELAND et al, 2002). Em alguns países como Holanda, Alemanha e Escandinávia, as filosofias que formam a base da governança corporativa sugerem que as ações de uma empresa devem estar direcionadas à garantia da sua continuidade e não apenas à busca da maximização do valor para o acionista. Entretanto, na maioria dos países desenvolvidos, a criação de valor para os acionistas mostra-se uma prática comum por parte da alta administração. Outro aspecto que merece destaque é o de que as economias voltadas à criação de valor para os acionistas parecem ter melhor desempenho quando comparadas a outros modelos econômicos (COPELAND et al, 2002).

O valor de mercado das empresas migra dos modelos de negócios que estão "pior avaliados” para os modelos que estão “melhor avaliados” na ótica dos acionistas, que optam por negócios que oferecem probabilidades de fluxos futuros de caixa relativamente maiores. Um modelo de negócio (business design) pode ser entendido com o conjunto de decisões e ações de uma empresa que influenciam diretamente o seu desempenho por meio da seleção dos seus clientes, proposição básica de valor, diferenciação de suas ofertas, adoção de critérios para a escolha das tarefas que realizará e que serão terceirizadas e configuração de seus processos e recursos. (SLYWOTZKY, 1997).

$\mathrm{Na}$ indústria farmacêutica, a competitividade deriva da oferta de produtos com mais valor ao mercado de consumo e na oferta de tecnologia ao mercado organizacional do setor de saúde, mas o valor encontra-se inserido em um sistema de relacionamentos e de atividades que representam o negócio da empresa. Nesse contexto, a migração de valor pode ocorrer em 


\section{MIGRAÇÃO DE VALOR NA INDÚSTRIA FARMACÊUTICA ${ }^{1}$}

vários níveis, afetando desde uma divisão específica da empresa até um setor como um todo, sendo que o processo de migração ocorre à medida que os acionistas efetuam suas escolhas sobre as concepções de negócios mais adequadas ao atendimento dos seus interesses. Dessa forma, o valor pode migrar para outros negócios dentro de um mesmo setor ou pode movimentar-se de um setor "pior avaliado" para um setor "melhor avaliado" que atenda à prioridade dos acionistas e tenha perspectivas de gerar maiores lucros (SLYWOTZKY, 1997).

O tamanho da organização, mensurável em termos de receita, relaciona-se cada vez menos com a capacidade de sua concepção de negócio criar valor, ou com o valor de mercado da empresa. Há uma crescente desconexão entre o tamanho das empresas e o seu valor, e observa-se que nas empresas novas e de pequeno porte, emergem as concepções de negócio mais inovadoras e poderosas para capturar a maior parte do crescimento do valor dos setores. Dadas estas tendências, a força da concepção de um negócio por ser avaliada por meio do valor de mercado relativamente ao faturamento da empresa, e não apenas por meio do faturamento, que é o critério mais corrente. Ao utilizar a receita como uma estimativa do tamanho da empresa, a proporção entre o valor de mercado e a receita nos permite comparar a força de criação do valor de diferentes concepções de negócios (SLYWOTZKY, 1997).

\section{METODOLOGIA}

Visando atingir o objetivo de melhor entender a migração de valor entre empresas da indústria farmacêutica, a presente pesquisa, que tem caráter exploratório, fundamenta-se na criação de séries históricas de vendas e valor de mercado das empresas para o período de 1998 a 2007 e na busca de indicadores que ajudem explicar a migração, como: as pesquisas em desenvolvimento, os produtos a serem aprovados, as fusões, as aquisições e os acordos operacionais. Os meios utilizados para a realização deste trabalho fundamentam-se na pesquisa bibliográfica e na pesquisa documental baseada na leitura sistematizada de relatórios anuais das empresas, banco de dados privados e de organizações públicas relativos ao setor

O universo da pesquisa é composto por 416 empresas farmacêuticas de capital aberto na Bolsa de Valores de Nova Iorque independentemente de seu porte. O valor de mercado destas empresas foi calculado multiplicando-se o total das ações (shares outstanding) pelo preço de fechamento das ações em 31 de dezembro de cada ano - esta data foi escolhida devido aos dados das vendas no banco de dados da Reuters serem nela referenciados, - e adicionando-se a dívida de longo prazo (long term debt), e as vendas foram extraídas diretamente do banco de dados do MSN Money e dos relatórios anuais das empresas.

Após a análise das 416 empresas, verificou-se que apenas 46 tinham os dados do valor de mercado e das vendas no período de 1998 a 2007, e estas definem de forma não probabilística e por acessibilidade a nossa amostra. Estas 46 empresas foram classificadas de acordo com a receita anual. A escolha do critério da classificação por meio das receitas anuais deveu-se principalmente à prática dos laboratórios farmacêuticos investirem em média 20\% do valor de suas receitas em pesquisa e desenvolvimento, sendo que, devido a esta prática a receita exerce uma influência direta na competitividade das empresas. Esta classificação gerou para efeito deste estudo cinco grupos de empresas: o primeiro grupo formado por cinco empresas com receitas anuais entre acima de US\$29,5 bilhões; o segundo formado por sete empresas com receitas entre US\$ 12,0 bilhões e US\$ 29,5 bilhões; o terceiro formado por doze empresas com receitas entre US\$ 1,0 bilhão e US\$12,0 bilhões; o quarto por quatorze 
empresas com faturamento entre 100 milhões e 1 bilhão de dólares, e o quinto grupo formado por empresa com faturamento de até 100 milhões de dólares ao ano.

Após esta classificação por porte, dentro de cada grupo, as empresas foram ordenadas com base no crescimento valor de mercado de 1998 a 2007. O ordenamento do crescimento do valor possibilita uma visualização dos negócios “melhor avaliados” e “pior avaliados” na ótica dos acionistas em cada faixa de receita e descreve o quadro de migração de valor entre empresas. Com estes resultados descritivos partiu-se para o estudo qualitativo dos fatores de competitividade que potencialmente influenciaram a migração de valor na indústria farmacêutica. A coleta de dados das empresas foi realizada por meio dos relatórios anuais disponíveis nos relatórios de relacionamento com investidores acessados por meio dos sítios das empresas, no MSN Money e Yahoo Finance - páginas na Internet que disponibilizam informações do banco de dados da Reuters, dados secundários, e, finalmente, nos arquivos da Securities and Exchange Comission - Washington D.C. - disponíveis no banco de dados da Séc fillings e Forms (Edgar). A escolha dessas fontes de pesquisa se deu em razão do registro dos dados serem confiáveis e representarem a compilação das informações internas e externas das empresas farmacêuticas que são disponibilizadas por força de lei ao mercado.

\section{ANÁLISE DOS RESULTADOS}

O setor de cuidados com a saúde (Healthcare), segundo o Yahoo Finance (2008) tinha uma capitalização de mercado de US\$ 2,2 trilhões em abril de 2008 enquanto a categoria dos maiores fabricantes de medicamentos apresentava uma capitalização ou valor de marcado de US\$ 1,2 trilhões, ou 52\% do setor. Deste total, os maiores laboratórios farmacêuticos (J\&J, Pfiser, GSK, Novartis, Sanofi Aventis, Merck, Abbott, Astra Zeneca, Wyeth, Elli Lilly, Bristol Mayers, Schering Ploug e Roche) somavam US\$ 1,13 trilhões e os laboratórios analisados neste estudo - todos os anteriores exceto a Novartis e a Roche - um total de US\$ 944,6 bilhões, ou seja, 81\% do valor dos maiores fabricantes.

Os 47 laboratórios analisados foram classificados em cinco faixas de receita, e a evolução das vendas e do valor de mercado por faixa de receita está descrita na tabela 1. As faixas foram ordenadas em função da ordem crescente da variação do valor das empresas entre os biênios 2006/07 e 1998/99, que compõe um período médio de nove anos. Observa-se que no total houve um crescimento de $92 \%$ na receita dos laboratórios amostrados, mas o valor de mercado cresceu apenas $13 \%$, e implicando que o coeficiente de valor sobre receita, que é um indicador importante de qualidade dos modelos de negócios, tenha caído de 6,5 vezes para 3,9 vezes. Consistentemente com a abordagem da migração de valor da revisão bibliográfica, observa-se que o valor migrou das empresas de porte maior para as empresas de porte menor. Como reflexo, as empresas com faturamento acima de US\$12 bilhões tiveram sua participação no valor total das empresas amostradas reduzida de 93,4\%, em 1998/99, para $77,2 \%$, em 2006/07. Por outro lado, os laboratórios de menor porte, com receita de até US\$12 bilhões tiveram um aumento de participação no valor de mercado de 6,6\% para 22,8\%.

Tabela 1-Receita e valor de mercado das empresas em US\$ bilhões por faixa de receita em US\$ bilhões em 2007

\begin{tabular}{l|ll|l}
\hline Faixas de & Média por empresa (2006/07) & Receita média anual no biênio $\quad$ Valor de mercado médio anual no biênio & Var. \% \\
\hline
\end{tabular}




\begin{tabular}{|c|c|c|c|c|c|c|c|c|c|c|c|c|c|c|}
\hline $\begin{array}{l}\text { Receita } \\
\text { (US\$ } \\
\text { Bilhões) }\end{array}$ & $\begin{array}{l}\text { No. } \\
\text { Emp. }\end{array}$ & Receita & Valor & $\begin{array}{l}\text { Valor/ } \\
\text { Receita }\end{array}$ & 1998/99 & $\%$ & 2006/07 & $\%$ & $\begin{array}{l}\text { Var. \% } \\
\text { Biênios }\end{array}$ & 1998/99 & $\%$ & $2006 / 07$ & $\%$ & Biênios \\
\hline De 12 a 30 & 7 & 18,59 & 72,86 & 3,9 & 90,95 & $43,3 \%$ & 130,15 & $32,3 \%$ & 43 & 637,01 & $47,5 \%$ & 510,01 & $33,6 \%$ & -20 \\
\hline De 30 a 60 & 5 & 43,88 & 130,96 & 3,0 & 107,15 & $51 \%$ & 219,40 & $54,4 \%$ & 105 & 615,86 & $45,9 \%$ & 654,79 & $43,1 \%$ & 6 \\
\hline Até 0,1 & 9 & 0,03 & 0,19 & 6,8 & 0,16 & $0,1 \%$ & 0,25 & $0,1 \%$ & 60 & 1,36 & $0,1 \%$ & 1,71 & $0,1 \%$ & 25 \\
\hline De 0,1 a 1 & 14 & 0,86 & 4,40 & 5,1 & 5,49 & $2,6 \%$ & 11,98 & $3,0 \%$ & 118 & 27,46 & $2,0 \%$ & 61,60 & $4,1 \%$ & 124 \\
\hline De 1 a 12 & 12 & 3,43 & 24,19 & 7,0 & 6,12 & $2,9 \%$ & 41,22 & $10,2 \%$ & 574 & 58,69 & $4,4 \%$ & 290,25 & $19,1 \%$ & 395 \\
\hline Total & 47 & 8,57 & 32,31 & 3,8 & 209,86 & $100 \%$ & 403,00 & $100 \%$ & 92 & $1.340,38$ & 100 & $1.518,37$ & $100 \%$ & 13 \\
\hline
\end{tabular}

Fonte: MSN Money (2008) e Annual Report das empresas

A migração de valor dentro da indústria farmacêutica pode ser explicada por meio da tabela 2, na qual classificamos as mesmas empresas em função de suas especialidades. No período analisado, os tradicionais laboratórios de grande porte e multiespecialistas, representados na amostra por 12 empresas com receita média de US\$ 28 bilhões, tiveram uma perda de valor de $10 \%$ nos nove anos considerados, enquanto os laboratórios mais especializados, e com receita média de apenas US\$1,9 bilhão, tiveram um aumento de valor de 228\%, ou um crescimento de valor 3,6 vezes maior. Este movimento também se reflete no coeficiente de valor sobre receita, que no caso dos 35 laboratórios menores é de 6,3, ou quase o dobro que o coeficiente de 3,3 dos grandes laboratórios multiespecialistas. Entre as empresas que mais têm atraído os investimentos dos acionistas estão os laboratórios especializados em biotecnologia e biofármacos, que diferentemente dos laboratórios tradicionais que produzem os fármacos sintetizados quimicamente, criam medicamentos com base em processos biológicos. Estes laboratórios, por serem menores e mais flexíveis, encontram-se na fronteira do conhecimento e além de produzirem remédios mais rentáveis nos dias atuais criam mais valor para os acionistas por produzirem melhores expectativas de resultados futuros. A participação destas duas especialidades no valor total das empresas pesquisadas triplicou de 9,1\%, em 1998/99, para 27,7\%, em 2006/07. As áreas terapêuticas pesquisadas por estas empresas são descritas no relatório Business Insight - The Blockbuster Drug Outlook (2007) o qual afirma que os produtos para o tratamento da asma, câncer, depressão, diabetes, hiperlipidemia, hipertensão e HIV, nos quais se concentram, têm potencial após o seu lançamento de gerar receitas acima de um bilhão de dólares ano.

A análise dos investimentos em $P \& D$ nas 47 empresas reforça o fato de que a manutenção na liderança do segmento farmacêutico e do posicionamento na fronteira dos novos conhecimentos exige foco, especialização e dispendiosos esforços por meio do desenvolvimento de moléculas, processos de produção e produtos com proteção de patentes, e alto retorno comercial. No biênio 2006/07 foi observado, conforme tabela 3, investimento médio em P\&D de 30\% sobre a receita e nas empresas de biotecnologia e biofármacos, 20\% nas multiespecialistas e $10 \%$ nas de genéricos. Observa-se que, consistententemente com a própria tendência das vendas, o crescimento de investimento em $\mathrm{P} \& \mathrm{D}$ nas empresas de biotecnologia e biofármacos, de $610 \%$, foi muito maior que nas empresas multiespecialistas, de $72 \%$, refletindo-se na maior capacidade de criação de valor destas empresas.

As empresas de genéricos apesar do baixo volume investido (1/3 do investimento relativo às vendas das empresas de biotecnologia e biofármacos) demonstraram um grande crescimento no período de 1998 a 2007. Os laboratórios de genéricos analisados tiveram um crescimento de valor de 59\%, face à queda de valor de $10 \%$ dos grandes concorrentes multiespecialistas. Há grandes dúvidas no setor sobre as perspectivas do segmento de 
genéricos e de seu impacto sobre os laboratórios tradicionais. Alguns laboratórios multiespecialistas tradicionais, como a Novartis, resolveram investir também no segmento de genéricos, por meio da Sandoz, por precaução. Há falta de foco pode implicar, entretanto, em perda de competitividade nos dois segmentos. Outros laboratórios resolveram se concentrar na pesquisa de drogas mais sofisticadas, aproximando-se dos segmentos de biotecnologia e biofármacos, inclusive por meio de participação acionária nestas empresas, como é o caso da Roche que investiu na Genentech, e após o grande sucesso desta acabou adquirindo $100 \%$ de suas ações. Este fato acontece em 75\% dos casos onde um grande laboratório faz parcerias e alianças estratégicas para o desenvolvimento de novas drogas com as empresas menores especializadas em biofármacos e biotecnologia (COPELAND et all, 2003).

Tabela 2 - Receita e valor de mercado das empresas em US\$ bilhões por especialidade produtiva

\begin{tabular}{|c|c|c|c|c|c|c|c|c|c|c|c|c|c|c|}
\hline \multirow{2}{*}{ Especialidade } & \multicolumn{4}{|c|}{ Média por empresa (2006/07) } & \multicolumn{4}{|c|}{$\underline{\text { Receita média anual do Biênio }}$} & \multicolumn{5}{|c|}{$\underline{\text { Valor de mercado médio anual no biênio }}$} & \multirow{2}{*}{$\begin{array}{l}\text { Var. \% } \\
\text { Biênios }\end{array}$} \\
\hline & $\begin{array}{l}\text { No. } \\
\text { Emp }\end{array}$ & eceita & Jalor & $\begin{array}{l}\text { Jalor/ } \\
\text { Receita }\end{array}$ & 1988/99 & $\%$ & 2006/07 & $\%$ & $\begin{array}{l}\text { Var.\% } \\
\text { Biênios }\end{array}$ & 1998/99 & $\%$ & 2006/07 & $\%$ & \\
\hline Multiespecialistas & 12 & 27,9 & 90,8 & $\overline{3,3}$ & 195,2 & 93 & 335 & $83,2 \%$ & 72 & 1210,0 & $90,3 \%$ & 1090,4 & $71,8 \%$ & $-10 \%$ \\
\hline Genéricos & 4 & 1,41 & $\overline{3,39}$ & 2,4 & 1,5 & 0,7 & 5,6 & $0,1 \%$ & 60 & 1,36 & $0,1 \%$ & 1,71 & $0,9 \%$ & $59 \%$ \\
\hline Biotecnologia & 19 & 2,06 & 14,9 & 7,3 & 6,3 & 3 & 39 & $3,0 \%$ & 118 & 27,46 & $2,0 \%$ & 61,60 & $18,7 \%$ & $233 \%$ \\
\hline Biofármacos & 12 & 1,93 & 10,9 & 5,7 & 6,9 & 3,3 & 23,2 & $10,2 \%$ & 574 & 58,69 & $4,4 \%$ & 290,25 & $9,0 \%$ & $257 \%$ \\
\hline Total & 47 & 8,57 & 32,3 & 3,8 & 209,9 & 100 & 403 & $100 \%$ & 92 & 1340,4 & $100 \%$ & 1518,4 & $100 \%$ & $13 \%$ \\
\hline
\end{tabular}

Fonte: MSN Money (2008) e Annual Report das empresas

Tabela 3 - Investimentos em P\&D em US\$ bilhões

\begin{tabular}{|c|c|c|c|c|c|c|c|c|}
\hline \multirow[t]{2}{*}{ Especialidade } & \multirow{2}{*}{$\begin{array}{l}\text { No. } \\
\text { Emp. }\end{array}$} & \multicolumn{3}{|c|}{$\begin{array}{l}\text { Investimento médio bienal nas } \\
\text { especialidades em US\$ bilhões }\end{array}$} & \multicolumn{2}{|r|}{$\begin{array}{c}\text { Variação do Investimento } \\
\text { em P\&D entre biênio }\end{array}$} & \multicolumn{2}{|c|}{$\begin{array}{l}\text { Investimento em } \\
\text { P\&D/Receita }\end{array}$} \\
\hline & & 1998/99 & $\%$ & 2006/07 & $\%$ & $(2006 / 07) /(1998 / 99)$ & 1998/99 & 2006/07 \\
\hline Multiespecialistas & 12 & 39,04 & $83,18 \%$ & 67,04 & $77,71 \%$ & $72 \%$ & $20,0 \%$ & $20,0 \%$ \\
\hline Genéricos & 4 & 0,15 & $0,31 \%$ & 0,56 & $0,64 \%$ & $273 \%$ & $10,0 \%$ & $10,0 \%$ \\
\hline Biotecnologia & 19 & 0,56 & $12,08 \%$ & 11,7 & $13,56 \%$ & $1989 \%$ & $8,9 \%$ & $30,0 \%$ \\
\hline Biofármacos & 12 & 2.07 & $4,41 \%$ & 6,96 & $8,06 \%$ & $236 \%$ & $30,0 \%$ & $30,0 \%$ \\
\hline Total da Amostra & 47 & 46,93 & $100 \%$ & 86,26 & $100 \%$ & $184 \%$ & $24,4 \%$ & $21,4 \%$ \\
\hline
\end{tabular}

Fonte: MSN Money (2008) e Annual Report das empresas

Nas seções a seguir detalha-se a composição das cinco faixas de receita descritas acima e busca-se compreender a migração de valor dos laboratórios que perderam valor favoravelmente àqueles que tiveram aumento de valor. Esta migração de valor reflete os fluxos de investimentos dos acionistas, e a própria competitividade das empresas não apenas no momento atual, mas principalmente numa perspectiva de prazo mais longo, dado que o valor de uma empresa tecnicamente é o valor presente de um fluxo de caixa descontado.

\subsection{Receita de US\$ 29,5 a US\$ 60 bilhões (Grande porte e multiespecialidades)}

Há um grupo de apenas 5 laboratórios que concentra capitalização de US\$ 655 bilhões, 43\% da amostra, e receitas de US\$ 219 bilhões, ou 54\% da amostra, em 2007. Todos são classificados como multiespecialistas, e sua evolução está descrita na tabela 3. 
A evolução do valor destas empresas pode ser explicada com base na afirmação de Lev (2000) que, ao utilizar como exemplo a indústria farmacêutica, demonstrou que um medicamento, ao ser aprovado em testes clínicos, cria um valor enorme, mesmo antes de sua comercialização. A análise do valor no período de 1998 a 2007 indica que, apesar do maior faturamento ser o da J\&J e o da GSK a maior variação do valor de mercado no período pertence a Novo Nordisk, com um crescimento de 225\% no período de 1998 a 2007, e a sua participação no valor total deste grupo passou de $2 \%$ para $5 \%$.

Tabela 4 - Receita e valor em US\$ bilhões de empresas com receita entre 30 a 60 Bilhões de US\$/ano em 2007

\begin{tabular}{|c|c|c|c|c|c|c|c|c|c|c|}
\hline \multirow[t]{2}{*}{ Empresas ${ }^{1}$} & \multicolumn{4}{|c|}{ Receita média anual no biênio } & \multirow{2}{*}{$\begin{array}{l}\text { Var. \% } \\
\text { Biênios }\end{array}$} & \multicolumn{4}{|c|}{ Valor de Mercado Médio Anual no Biênio } & \multirow{2}{*}{$\begin{array}{l}\text { Var. \% } \\
\text { Biênios }\end{array}$} \\
\hline & 1998/99 & $\%$ & 2006/07 & $\%$ & & 1998/99 & $\%$ & 2006/07 & $\%$ & \\
\hline$\overline{\text { Pfiser }}$ & 25,2 & 24 & 48,4 & 22 & 92 & 232,0 & 38 & 193,9 & 30 & -16 \\
\hline$\overline{\text { GSK }}$ & 26,9 & 25 & 45,5 & 21 & 69 & 177,4 & 29 & 152,2 & 23 & -14 \\
\hline Astra & 13,9 & 13 & 28 & 13 & 103 & 59,9 & 10 & 78,3 & 12 & 31 \\
\hline $\mathrm{J} \& \mathrm{~J}$ & 26,2 & 24 & 57,2 & 26 & 118 & 135,8 & 22 & 195,1 & 30 & 44 \\
\hline N. Nordisk & 15,1 & 14 & 40,3 & 18 & 168 & 10,9 & 2 & 35,3 & 5 & 225 \\
\hline Valor Total & 107,2 & $\overline{100}$ & 219,4 & 100 & 105 & 615,9 & $\overline{100}$ & $\overline{654,8}$ & $\overline{100}$ & 6 \\
\hline
\end{tabular}

Fonte: MSN Money (2008) e Annual Report das empresas

(1) Empresas multiespecialistas

A Novo Nordisk apresenta fortemente a característica descrita por Lev (2000), pois, a empresa tem forte atuação em áreas como distúrbios de coagulação, hormônios do crescimento, terapia de reposição hormonal e oferece serviços especializados de suporte que fazem diferença significativa para os pacientes, profissionais de saúde e a sociedade. O uso contínuo de seus produtos protegidos por patentes garante retornos acima da média. Apesar de investir em média apenas 15\% do seu faturamento em P\&D (valor em média 25\% menor que o das outras empresas nesta categoria em relação às vendas) os esforços de pesquisa estão focados na área de diabetes (seis produtos injetáveis e um de uso oral em desenvolvimento); dois biofármacos para utilização em hemorragias, um produto para problemas renais crônicos que necessitam de diálise, dois produtos para terapia de reposição hormonal e dois para o tratamento do câncer maligno, totalizando 13 patentes pipeline (patentes cedidas para moléculas e produtos em estágio de estudo clínico). Apesar do número de pipelines ser bem inferior aos da Pfizer e da GSK, líderes em faturamento e com 100 patentes pipeline em média cada uma, o destaque da Novo Nordisk é o fato de que se concentra em duas áreas promissoras - diabetes e câncer - para novos produtos nos próximos cinco anos entre as cinco previstas no relatório Business Insight - The Blockbuster Drug Outlook (2007) - Asma, Câncer, Depressão, Diabetes, Hiperlipidemia, Hipertensão e HIV. Ressalte-se que a empresa é a líder mundial no tratamento da diabetes, fato que contribuiu para o grande crescimento do valor no período de 1998 a 2007. Em termos de aquisições, fusões e parcerias a Novo Nordisk, não fez nenhum tipo de parceria, ficando claro que a Novo Nordisk desenvolveu uma estratégia segundo Copeland et al (2002) fortemente direcionada à governança corporativa - tipicamente europeia - contrariando as tendências do setor.

A segunda empresa com maior crescimento de valor foi a Johnson \& Johnson, mas devido ao fato de a participação do setor farmacêutico na receita total da J\&J ser de apenas 15\%, ela foi excluída da avaliação. Desta forma, a segunda empresa com a melhor evolução 
do valor foi a AstraZeneca, que possui produtos em desenvolvimento na área cardiovascular, gastrointestinal, sistema nervoso, oncologia, infecções por vírus e linha respiratória somando um total de 100 produtos em desenvolvimento. Todas estasáreas, com exceção da gastrointestinal, são promissoras para o surgimento de um produto com faturamento de anual de US\$ 1 bilhão, que seria o que o meio farmacêutico denomina supermedicamento e, além disso, o laboratório já lançou o Nexium (novo antio-ácido), que foi o segundo em vendas no mundo em 2006 e o terceiro em 2007 (IMS Health, 2008).

Os líderes em valor absoluto desta categoria (Pfiser com US\$193 bilhões e GSK com US\$153 bilhões no biênio de 2006/07) realizam expressivo investimento em P\&D, que representa $20 \%$ do seu faturamento anual e gera cerca de 100 patentes pipeline para cada empresa. Adicionalmente, realizaram aquisições de grande porte e também várias parcerias estratégicas com empresas especializadas para o desenvolvimento de novos produtos em áreas terapêuticas promissoras, visando a criação de valor para os acionistas. Cabe destacar, entretanto, que estas parcerias de forma geral valorizaram mais as ações das outras empresas do que das grandes, como foi o caso da Pfiser, que em 2005 fez uma aliança com a OSI Pharmaceutical para o desenvolvimento e promoção do Macugen - um importante medicamento para a prevenção da cegueira - em todos os mercados fora dos Estados Unidos. No período 2006/07 em relação à 1998/99 o valor da OSI cresceu 1250\%, passando de 1\% do valor das empresas da categoria para 8\%, conforme a tabela 7, enquanto o da Pfiser caiu 16\%.

A Glaxosmithkline, terceira empresa em valor da categoria, também promoveu inúmeras alianças estratégicas no período analisado, entre as quais se destacam as seguintes: a) em 2006 realizou aliança com a Chemo Centrix, empresa de biofármacos, para o desenvolvimento de medicamentos para o câncer e doenças inflamatórias.; b) também em 2006, firmou uma aliança com a Epix Pharmaceutical - uma empresa especializada em biofármacos para o tratamento de doenças do sistema nervoso central - para pesquisa desenvolvimento e comercialização; c) em dezembro de 2007, aliança com a OncoMed, para a pesquisa e desenvolvimento de moléculas para o tratamento do câncer; d) em outubro de 2007, a Glaxosmithkline e a Anacor (empresa americana de pesquisa em biofármacos), anunciaram uma aliança estratégica mundial para o desenvolvimento e comercialização de novos medicamentos para o tratamento de vírus e bactérias e, com este acordo a GSK passou a ter acesso a boron-based chemistry uma tecnologia para o desenvolvimento racional de moléculas de propriedade da Anacor; e) em dezembro de 2007 a GSK e a Oncomed Pharmaceuticals anunciaram uma aliança estratégica mundial para descobrir, desenvolver e comercializar novos medicamentos para o tratamento do câncer;f) outra aliança estratégica no ano de 2007 foi com a Santaris Pharma uma empresa que desenvolve biofármacos e possuí uma tecnologia de desenvolvimento de compostos do ARN (ácido ribonucleico) para o desenvolvimento de medicamentos para o tratamento do câncer e de doenças provocadas por vírus;g) em julho de 2007, a GSK anunciou uma aliança estratégica com a Targacept, uma empresa de pesquisa em biotecnologia, sendo que com esta aliança, a GSK terá acesso à tecnologia exclusiva da Targacept chamada neuronal nicotinic receptors (NNRs) que desenvolve moléculas para o tratamento de doenças e desordens do sistema nervoso central.

Os excelentes resultados no crescimento do valor, principalmente das adquiridas, por meio das fusões, aquisições e alianças estratégicas efetuadas pela Pfizer e pela GSK podem 
ser suportados por Upton (2001), ao afirmar que os ativos intangíveis como recursos não físicos, são geradores de prováveis benefícios econômicos futuros para a empresa, e que estes podem ser obtidos por aquisições, fusões, alianças ou desenvolvidos internamente. Para Copeland et al (2002) as alianças são importantes para o desenvolvimento de novos mercados, compartilhamento dos custos de desenvolvimento e compartilhamento de riscos. Outro importante aspecto abordado pelo autor é o de que $75 \%$ das alianças terminam em aquisição, e isto explica parcialmente a grande valorização da empresas que fecham alianças com os líderes em valor do mercado.

\subsection{Receita de US\$ 12 a US\$ 29,5 bilhões (Médio porte e multiespecialidades)}

Ao analisarmos as empresas farmacêuticas de médio porte destaca-se o fato que estas são formadas em sua maioria por empresas de multiespecialidades médicas com marcas conhecidas no mercado farmacêutico, entretanto, nesse grupo temos como destaque a participação da Amgen, uma empresa especializada em biotecnologia. A Amgen, embora uma das menores empresas em volume de receita, registrou o maior crescimento de valor, $72 \%$ no período analisado, conforme a tabela 5. A Amgen é uma empresa líder mundial em biotecnologia, e faturou 25,9 bilhões de dólares em 2007 atuando nos principais mercados ao redor do globo como Estados Unidos, Canadá, México, Europa, Austrália e Ásia, sendo que 55\% da receita está concentrada nos Estados Unidos. A Amgen investe aproximadamente $25 \%$ do seu faturamento em pesquisa e desenvolvimento, e os produtos estão direcionados para as áreas de suporte e cuidados oncológicos, nefrologia e inflamação (AMGEN, 2008). Em relação à criação de valor para os acionistas a empresa realizou aquisições e alianças que lhe proporcionaram um forte crescimento: em 1994, a Synergen, com produtos em fase final de desenvolvimento para tratamento de inflamações; em 1999 a empresa comprou a Praecis; em 2000, a Kinetix; em 2002, a Immunes; em 2004, a Tularik; e em 2007, adquiriu a Alantos, além de várias outras joint ventures (AMGEN, 2008). Estas ações evidenciam uma estratégia de criação de valor para os acionistas por meio de aquisições focadas em áreas terapêuticas com grande potencial de retorno, segundo Copeland et al (2003).

As três empresas com maior crecimento de valor (Amgen, Eli Lilly e Wyeth), têm um número de patentes pipeline bem superior ao da primeira (Bristol) e segunda (Merck) pior avaliadas em variação do valor.. Outro fator de competitividade que merece destaque é o investimento em $P \& D$, enquanto a Amgen investe 25\% da receita em P\&D, e a Lilly e Wyeth $20 \%$, a Bristol investe apenas $10 \%$, o que proporcionalmente representa um investimento conservador em pesquisa e desenvolvimento. Sobre este aspecto, Lev (2001) sustenta que o aumento do interesse sobre os ativos intangíveis está relacionado à combinação de duas forças econômicas: o aumento da competição entre as empresas e a evolução da tecnologia.

Tabela - 5 Receita e valor em US\$ bilhões de empresas com receita entre 12 e 29 Bilhões de US\$/ano em 2007

\begin{tabular}{|c|c|c|c|c|c|c|c|c|c|c|}
\hline \multirow[t]{2}{*}{ Empresas } & \multicolumn{4}{|c|}{ Receita média anual no biênio } & \multirow{2}{*}{$\begin{array}{l}\text { Var. \% } \\
\text { Biênios }\end{array}$} & \multicolumn{4}{|c|}{ Valor de mercado médio anual no biênio } & \multirow{2}{*}{$\begin{array}{l}\text { Var.\% } \\
\text { Biênios }\end{array}$} \\
\hline & 1998/99 & $\%$ & 2006/07 & $\%$ & & 1998/99 & $\%$ & 2006/07 & $\%$ & \\
\hline Bristol $^{2}$ & 15,8 & 17 & 18,3 & 14 & 16 & 132,5 & 21 & 58,7 & 12 & -56 \\
\hline Schering $^{2}$ & 8,6 & 9 & 11,6 & 9 & 35 & 73,1 & 11 & 44,8 & 9 & -39 \\
\hline Merck $^{2}$ & 29,8 & 33 & 23,4 & 18 & -22 & 168,9 & 27 & 110,8 & 22 & -34 \\
\hline Eli Lilly ${ }^{2}$ & 9,6 & 11 & 17,1 & 13 & 78 & 88,0 & 14 & 62,1 & 12 & -29 \\
\hline Wyeth ${ }^{2}$ & 11,5 & 13 & 21,3 & 16 & 85 & 66,0 & 10 & 72,1 & 14 & 9 \\
\hline Abbott ${ }^{2}$ & 12,8 & 14 & 24,2 & 19 & 89 & 65,3 & 10 & 86,9 & 17 & 33 \\
\hline
\end{tabular}




\begin{tabular}{l|lllllllll|l}
\hline Amgen $^{1}$ & 3,0 & 3 & 14,5 & 11 & 382 & 43,3 & 7 & 74,7 & 15 & 72 \\
\hline Valor Total & 91,0 & 100 & 130,2 & 100 & 43 & 637,0 & 100 & 510,0 & 100 & -20
\end{tabular}

Fonte: MSN Money (2008) e Annual Report das empresas

(1) Empresa de biotecnologia; (2) Empresas multi-especialistas

A fusão da Bristol e Squibb não trouxe resultados significativos, fazendo com que o valor da Bristol Mayers Squibb (BMS) caísse 56\% no período analisado, a despeito da estratégia de parcerias com empresas de biotecnologia, incluindo a parceria com a Sanofi. A falta de grandes fusões e aquisições com resultado comercial efetivo e o baixo investimento em P\&D no período de 1998 a 2007 resultaram na ausência de um produto realmente promissor de propriedade exclusiva da empresa que pudesse alavancar o valor de mercado da BMS. Seu único sucesso resultou de uma parceria com a Sanofi, em 2001, para o desenvolvimento e comercialização do PLAVIX, um produto para o tratamento de arterio-trombose. Este remédio esteve desde o ano de 2003 entre os cinco mais prescritos, e em 2005 obteve a segunda colocação no ranking de produtos mais prescritos (IMS HEALTH, 2005) colaborando para a evolução das receitas anuais da empresa com o faturamento de US\$ 3,7 bilhões/ano, ou cerca de 25\% da receita total (MSN Money, 2008).

\subsection{Receita de US\$1 a US\$12 bilhões (Pequeno porte; biotecnologia e biofármacos)}

O terceiro grupo de empresas é formado principalmente por empresas de biotecnologia e biofármacos, e as principais empresas em faturamento são a Genentech e a Teva. Neste grupo também aparecem algumas empresas fabricantes de produtos genéricos. O conjunto destas empresas teve aumento de receita (574\%) muito superior ao da média das 47 empresas analisadas no período (72\%). A Celgene destaca-se com o maior crescimento de valor no período analisado, 2523\%, seguida pela Gilead, 1669\%, e Teva, 838\%, conforme tabela 6.

Todas as empresas desta categoria, com destaque para as mencionadas no parágrafo acima e exceção as duas de genéricos, possuem produtos para doenças de alta complexidade ou tecnologia de ponta para desenvolvimento e produção de biofármacos e biotecnologia. A Genentech precisa ser destacada por ter sido a pioneira em biotecnologia e líder da categoria em valor com 29\% de participação no valor total nesta categoria de faturamento (tabela 6). Esta empresa iniciou suas operações em 1976, o que lhe garante a posição da empresa pioneira em biotecnologia, atua em nível global em parceria com a Roche, que se tornou sua controladoraa partir de 2000. As principais áreas terapêuticas que a empresa atua são: bioncologia, com quatro produtos, imunologia, com três produtos, e reparação e crescimento de tecidos, com oito produtos. Os esforços em P\&D representam aproximadamente o investimento de $25 \%$ de seu faturamento, e atualmente tem os seguintes produtos e moléculas em desenvolvimento: oito moléculas para o tratamento do câncer, duas para o tratamento da asma, uma para o infarto na fase I, nove moléculas para o tratamento do câncer na fase II de estudos clínicos, nove moléculas na fase III para o tratamento do câncer e duas para a Asma. O total de patentes pipeline e moléculas em desenvolvimento da Genentech representam potencial de 20 inovações divididas em 6 indicações terapêuticas e 14 produtos inovadores. 


\begin{tabular}{|c|c|c|c|c|c|c|c|c|c|c|}
\hline \multirow[t]{2}{*}{ Empresas } & \multicolumn{4}{|c|}{ Receita média anual no Biênio } & \multirow{2}{*}{$\begin{array}{l}\text { Var. \% } \\
\text { Biênios }\end{array}$} & \multicolumn{4}{|c|}{ Valor de mercado médio anual no biênio } & \multirow{2}{*}{$\begin{array}{l}\text { Var. \% } \\
\text { Biênios }\end{array}$} \\
\hline & 1998/99 & $\%$ & 2006/07 & $\%$ & & 1998/99 & $\%$ & 2006/07 & $\%$ & \\
\hline Watson $^{3}$ & 656,1 & 11 & $2.238,0$ & 5 & 241 & 4.917 & 8 & $3.752,5$ & 1 & -24 \\
\hline Sepracor ${ }^{1}$ & 16,5 & 0 & $1.204,2$ & 3 & 7.227 & 3.606 & 6 & $5.356,0$ & 2 & 49 \\
\hline Mylan ${ }^{3}$ & 755,7 & 12 & $1.875,0$ & 5 & 148 & 3.282 & 6 & $8.064,0$ & 3 & 146 \\
\hline Allergan 1 & $1.374,3$ & 22 & $3.444,6$ & 8 & 151 & 5.575 & 9 & $20.538,5$ & 7 & 268 \\
\hline Genentech $^{2}$ & 878,5 & 14 & $8.541,5$ & 21 & 872 & 21.944 & 37 & $83.813,0$ & 29 & 282 \\
\hline Genzyme $^{2}$ & 597,0 & 10 & $3.476,8$ & 8 & 482 & 4.218 & 7 & $18.459,5$ & 6 & 338 \\
\hline Cephalon ${ }^{1}$ & 14,3 & 0 & $1.723,8$ & 4 & 11.988 & 815 & 1 & $4.848,5$ & 2 & 495 \\
\hline Biogen ${ }^{2}$ & 102,5 & 2 & $2.927,4$ & 7 & 2756 & 2.631 & 4 & $16.807,5$ & 6 & 539 \\
\hline Shire ${ }^{1}$ & 333,7 & 5 & $2.098,1$ & 5 & 529 & 5.053 & 9 & $35.473,0$ & 12 & 602 \\
\hline Teva ${ }^{1}$ & $1.199,2$ & 20 & $8.908,0$ & 22 & 643 & 3.737 & 6 & $35.066,5$ & 12 & 838 \\
\hline Gilead $^{2}$ & 160,1 & 3 & $3.628,1$ & 9 & 2.167 & 2.133 & 4 & $37.723,5$ & 13 & 1.669 \\
\hline Celgene $^{2}$ & 28,7 & 0 & $1.152,4$ & 3 & 3.915 & 776 & 1 & $20.351,0$ & 7 & 2.523 \\
\hline Valor Total & $6.116,1$ & 100 & 41.217 & 100 & 574 & 58.686 & 100 & 290.253 & 100 & 395 \\
\hline
\end{tabular}

Fonte: MSN Money (2008) e Annual Report das empresas

(1) Empresa de biofármacos; (2) Empresas de biotecnologia; (3) Empresas de genéricos

A principal parceria da Genentech foi com a Roche, entretanto temos várias parcerias e aquisições que agregaram valor nas pesquisas e desenvolvimento de produtos nas áreas terapêuticas de atuação desta organização, sendo que algumas podem ser acompanhadas no histórico de desenvolvimento e de lançamento de produtos da empresa. Em 1998 foi aprovado pelo F.D.A. o Herceptin para o tratamento do câncer, em 2000 o TNKase para o tratamento do infarto do miocárdio, em 2001 foi aprovado pelo F.D.A. o Cathflo para a desobstrução de vasos no procedimento de cateterismo e o Activase para o tratamento do infarto do miocárdio. Este produto permite a oxigenação das áreas afetadas impedindo a morte do músculo cardíaco após o infarto. Em 2002 a empresa obteve a aprovação de um medicamento para facilitar a aplicação de um hormônio e um teste para a identificação de genes para o uso de Hercepetin. Em 2003 obteve a aprovação do Xolair para o tratamento da Asma e o Raptiva para o tratamento da Psoríase. Em 2004 o F.D.A. aprovou o Avastin para quimioterapia (este produto impede a metástase do câncer). Em parceria com a OSI Pharmaceutical obteve a aprovação do Tacerva, um medicamento de uso diário para impedir a metástase do câncer durante a quimioterapia. Em 2006 a Genentech obteve a aprovação do Lucentis, um medicamento para o tratamento da degeneração muscular e do Rituxan para o tratamento da Artrite (GENENTECH, 2008). Estes produtos representaram inovações a serem seguidas pelos concorrentes, significativa vantagem competitiva, e retornos financeiros acima da média da indústria, gerando um grande valor para os acionistas.

A Celgene é uma empresa de pesquisa intensiva em biofármacos fundada em 1980, que em 2007 atingiu a receita de US\$1,4 bilhão. Esta empresa investe 30\% do seu faturamento nas suas principais áreas terapêuticas: o tratamento de doenças por meio de células embrionárias a partir do cordão umbilical e da placenta, tratamento do câncer e antiinflamatórios para doenças autoimunes. A empresa atua em vários mercados ao redor do globo por meio de parcerias com outras empresas farmacêuticas. Os principais produtos de seu portfólio são: Revlomid (lenalidomide) para o tratamento do câncer (mieloma), Thalomid (talidomida) para o tratamento de inflamações causadas pelo câncer, e Alkeran (melphalan), 
que foi licenciado pela GSK para a distribuição pela Celgene nos Estados Unidos. A Celgene também é proprietária do Lifebank o primeiro banco de células do cordão umbilical e da placenta, sendo que esta empresa beneficia estas células, e do início de sua operação até o final de 2007 já havia atendido mais de 8000 pacientes com aproximadamente 80 doenças, entre as quais a Leucemia e doenças do sistema imunológico. As células depositadas no banco podem ser utilizadas pelos doadores ou parentes dos doadores (CELGENE, 2008). A partir de 2000 a empresa firmou uma parceria com a Novartis para pesquisa e desenvolvimento de novos produtos, e com outras pequenas empresas de pesquisa com foco nas áreas terapêuticas desenvolvidas pela Celgene (CELGENE, 2003).

A Gilead Sciences tem trabalhado desde 1987 para descobrir, desenvolver e comercializar medicamentos para o avanço no cuidado de pacientes que sofrem de doenças como o hipertensão, a fibrose cística, HIV e hepatite. Com sede em Foster City, Califórnia, a empresa expandiu-se rapidamente ao longo das últimas duas décadas, e suas operações abrangem três continentes (América do Norte, Europa e Austrália) com uma equipe de mais de 3.400 empregados. As áreas terapêuticas incluem: antivirais para o tratamento do HIV/SIDA e a hepatite crônica, condições cardiovasculares como a hipertensão arterial pulmonar e hipertensão resistente e as doenças respiratórias com foco na gripe e fibrose cística. A principal parceria da Gilead foi com a Hoffmann-La Roche, em 1996, para P\&D, e desde 1993 promoveu uma série de parcerias com empresas intensivas na pesquisa e desenvolvimento de fármacos por meio da biotecnologia.

Nesta faixa de receita a empresa pior avaliada foi a Watson, uma empresa fabricante de genéricos que não apresentou novidades tecnológicas no período e nenhuma aliança estratégica, e por este motivo sua participação no total da categoria que era de 8\% no biênio 1998/99 caiu para 1\% no biênio de 2006/07 (tabela 6). Como contrapartida a Mylan, também fabricante de genéricos, obteve um crescimentoem seu valor de $146 \%$ no mesmo período. A Mylan assumiu a liderança no setor de por meio da sua capacidade de obter aprovações em novas patologias e formas farmacêuticas para estes medicamentos. Adicionalmente a companhia expandiu as apresentações dos genéricos para além das suas aplicações tradicionais oferecendo variações como: dose unitária, suspensões, líquidos, transdérmicos e prorrogação na liberação do princípio ativo. $O$ investimento em investigação, desenvolvimento e instalações para a fabricação de produtos em uma variedade de sistemas de distribuição é outra das razões que a levaram à liderança no segmento de genéricos. A companhia tem realizado alianças estratégicas com várias empresas farmacêuticas e de distribuição por meio de acordos de licenciamento que fornecem à companhia outros produtos para ampliar a abrangência no segmento de genéricos. Além disso, a Mylan desenvolveu acordos de licenciamento, em que a companhia obtém o direito de fabricação e distribuição de outros produtos farmacêuticos em troca de financiamento para o desenvolvimento de novas aplicações dos genéricos. No segmento de produtos de marca a Mylan opera principalmente por meio da sua sucursal Bertek Pharmaceutical. A Bertek tem três áreas terapêuticas de concentração que incluem a cardiologia, neurologia e dermatologia. Na cardiologia os produtos foram originalmente desenvolvidos e fabricados pela American Home Products Corp adquirida no ano fiscal de 1997. A Mylan continua a expandir seus negócios no segmento de marcas por meio de sua área de $P \& D$ e por meio de aquisições. Visando 
expandir a sua presença em dermatologia, em 1998 a companhia adquiriu 100\% das ações da Penederm Inc. Bertek e, passou a desenvolver produtos patenteados.

\subsection{Receita de US\$100 milhões a US\$1 bilhão (Pequeno porte; biofármacos e biotecnologia)}

Na tabela 7 observa-se que as empresas que tiveram o maior aumento de valor foram a Lifecell, OSI e Cubist, e as com a pior evolução foram a Alpharma, Valeant e Cambrex.

Tabela 7 - Receita e valor em US\$milhões de empresas com receita entre 100 milhões e 1 Bilhão de US\$/ano em 2007

\begin{tabular}{|c|c|c|c|c|c|c|c|c|c|c|}
\hline \multirow[t]{2}{*}{ Empresas } & \multicolumn{4}{|c|}{ Receita média anual no Biênio } & \multirow{2}{*}{$\begin{array}{l}\text { Var. \% } \\
\text { Biênios }\end{array}$} & \multicolumn{4}{|c|}{$\underline{\text { Valor de mercado médio anual no biênio }}$} & \multirow{2}{*}{$\begin{array}{l}\text { Var. \% } \\
\text { Biênios }\end{array}$} \\
\hline & 1998/99 & $\%$ & 2006/07 & $\%$ & & 1998/99 & $\%$ & $2006 / 07$ & $\%$ & \\
\hline Cambrex $^{3}$ & 954,7 & 17 & 486,8 & 4 & -49 & 1.852 & 7 & 1.131 & 2 & -39 \\
\hline Valeant $^{1}$ & $1.585,5$ & 29 & $1.735,0$ & 14 & 9 & 4.835 & 18 & 4.256 & 7 & -12 \\
\hline Alpharma ${ }^{1}$ & $1.320,6$ & 24 & $1.376,3$ & 11 & 4 & 2.893 & 11 & 2.747 & 4 & -5 \\
\hline Millenium ${ }^{1}$ & 317,4 & 6 & $1.014,4$ & 8 & 220 & 6.402 & 23 & 8.969 & 15 & 40 \\
\hline Qiagen $^{3}$ & 279,0 & 5 & $1.115,6$ & 9 & 300 & 3.692 & 13 & 7.868 & 13 & 113 \\
\hline $\mathrm{CHTT}_{(\mathrm{OTC})}{ }^{1}$ & 518,2 & 9 & 723,9 & 6 & 40 & 1.274 & 5 & 3.115 & 5 & 145 \\
\hline Techne $^{3}$ & 158,2 & 3 & 426,1 & 4 & 169 & 1.511 & 6 & 4.804 & 8 & 218 \\
\hline Vertex 1 & 171,5 & 3 & 415,4 & 3 & 142 & 2.020 & 7 & 7.825 & 13 & 287 \\
\hline Inclone 3 & 6,3 & 0 & $1.268,7$ & 11 & 19.942 & 1.400 & 5 & 7.187 & 12 & 413 \\
\hline Market $^{3}$ & 11,4 & 0 & 577,5 & 5 & 4.974 & 319 & 1 & 1.761 & 3 & 452 \\
\hline Pharm Resource ${ }^{2}$ & 97,1 & 2 & $1.444,4$ & 12 & 1.388 & 286 & 1 & 1.595 & 3 & 458 \\
\hline Cubist $^{1}$ & 8,5 & 0 & 480,7 & 4 & 5.542 & 472 & 2 & 2.846 & 5 & 503 \\
\hline $\mathrm{OSI}^{3}$ & 47,8 & 1 & 582,1 & 5 & 1.117 & 386 & 1 & 5.212 & 8 & 1250 \\
\hline Lifecell $^{3}$ & 20,7 & 0 & 332,8 & 3 & 1.510 & 116 & 0 & 2.287 & 4 & 1872 \\
\hline Valor Total & $5.487,8$ & 100 & $11.979,6$ & 100 & 118 & 27.458 & 100 & 61.603 & 100 & 124 \\
\hline
\end{tabular}

Fonte: MSN Money (2008) e Annual Report das empresas

(1) Empresa de biofármacos; (2) Empresas de genéricos; (3) Empresas de biotecnologia

A LifeCell desenvolve e comercializa produtos para a reparação tecidual utilizados em reconstruções uroginecológicas, ortopédicas e cirúrgicas em geral. A LifeCell em 2008 comercializou os seguintes produtos que são bem sucedidos em sua categorias de tratamento: Strattice, para procedimentos cirúrgicos reconstrutivos e geral; AlloDerm, para plástica reconstrutiva, cirurgia geral, queimaduras e procedimentos periodontais; Cymetra, uma forma de partículas AlloDerm adequadas para injeção; Repliform, para procedimentos cirúrgicos uroginecologicos; GraftJacket, para procedimentos cirúrgicos ortopédicos e AlloCraft тм MCF, de procedimentos de enxerto ósseo. A empresa realizou várias alianças estratégicas com pequenas empresas e instituições de pesquisa altamente especializadas, e contou com fundos de associações para o desenvolvimento de sua linha de produtos.

Outra empresa bem avaliada nesta faixa de receita foi a OSI, uma empresa global da área de biotecnologia empenhada na descoberta e desenvolvimento de remédios para o tratamento do câncer, diabetes e obesidade. A estratégia desta empresa é a de comercializar seus produtos tanto de forma independente como em colaboração com grandes empresas farmacêuticas. A OSI investe em P\&D em média 65\% de sua receita/ano conforme o seu relatório anual de 2007, e os medicamentos e moléculas em desenvolvimento por áreas terapêuticas 
concentram-se em: oncologia, diabetes, obesidade e sistemas para identificação de proteínas e RNA para o desenvolvimento de biofármacos e biotecnologia. A sua principal parceira em desenvolvimento na área oncológica é a Glaxosmithkline, porém outras parcerias com empresas de menor porte altamente especializadas também foram realizadas.

A terceira empresa com maior evolução do valor foi a Cubist Pharmaceuticals, que é centrada na investigação, desenvolvimento e comercialização de produtos que tratam infecções em ambientes hospitalares. Cubicin(daptomicina injectável), é o primeiro antibiótico de classe IV, e foi o maior sucesso de vendas de um lançamento de antibiótico nos Estados Unidos. Uma comparação com a tendência histórica de vendas demonstra o significativo potencial de crescimento para Cubicin. O foco da empresa é a aquisição e desenvolvimento de novas aplicações para o Cubicin, e o desenvolvimento de programas que sejam cientificamente validos e comercialmente atraentes. A empresa desenvolveu uma aliança com a Dyax Corp, que está no estágio clínico de uma proteína recombinante humana para uso na prevenção de perda sanguínea durante as cirurgias. Este acordo dá o direito aos norte-americanos e à União Europeia para desenvolver e comercializar esta proteína recombinante. Além disso, tal como anunciado em julho de 2008, tem agora um acordo com a AstraZeneca para promover nos Estados Unidos o Merrem IV antibiótico. Este produto complementa o esforço comercial no Cubicin, permitindo a criação de uma nova fonte de receita corrente, alavancando as vendas e criando valor para os acionistas (CUBIST, 2008). O Cubist também possui duas promessas para o ano de 2009: um potente antibiótico para o tratamento da diarreia e um potente antibiótico para o tratamento de infecções hospitalares resistentes. Na categoria de empresas com faturamento de 100 milhões a 1 bilhão de dólares ao ano, foi observado um maior número de ações orientadas para as parcerias estratégicas, foco de mercado e P\&D nas empresas que tiveram a liderança de valorização, corroborando a importância de uma estratégia de criação de valor para o acionista fundamentada nos ativos intangíveis (COPELAND et al, 2002).

As empresas com a pior evolução do valor de mercado nesta categoria foram a Cambrex e Valeant, conforme a tabela 7. A Cambrex, que é uma fornecedora de produtos e serviços para desenvolvimento de biofarmacos, apresentou a maior queda de valor no período, que foi de -39\%. A empresa desenvolve plataformas para uso em pequenas moléculas, insumos farmacêuticos e aceleradores de síntese. A Cambrex possui vasta experiência no desenvolvimento de processos de fabricação de substâncias medicamentosas para uso em estudos de toxicidade, estudos clínicos e de abastecimento comercial. A empresa oferece uma ampla gama de serviços que incluem seleção, processo analítico e desenvolvimento, processo de otimização, avaliações de segurança, e processos para a formulação de produtos (CAMBREX, 2008). Entretanto a empresa não possui nem um produto farmacêutico, não realizou alianças e acordos estratégicos com grandes laboratórios que gerassem participação em patentes pipeline, e os produtos e serviços comercializados por ela possuem vários concorrentes. O desenvolvimento realizado por esta empresa é de propriedade dos outros laboratórios que são seus clientes.

A Valeant apresentou uma queda de $12 \%$ no seu valor. É uma empresa farmacêutica multinacional especializada em biotecnologia que desenvolve e comercializa produtos farmacêuticos para prescrição e uso hospitalar focada nas áreas terapêuticas de neurologia e 
dermatologia, principalmente nos Estados Unidos, Canadá, México, Brasil, Austrália e Europa Central. A Valeant adotou como estratégia a concentração nos pontos fortes da empresa - neurologia e dermatologia a partir de 2008, e maximizou seu pipeline por meio da parceria estratégica visando aperfeiçoar a investigação e desenvolvimento de novos produtos e reforçando a capacidade interna de desenvolvimento (VALEANT, 2008). Como exemplo, durante o ano de 2008 a empresa realizou avanços significativos por meio da alienação de seus direitos de licenciamento na Argentina, região da Ásia-Pacífico, Europa Ocidental e Oriental, Oriente Médio e África. Além disso, a Valeant assinou um acordo de parceria com a exclusividade mundial com a GSK para o Retigabine, um composto que está sendo testado em seres humanos para o tratamento de crises em doentes adultos com epilepsia refratária. A Valeant também realizou uma joint venture com Meda AB para reforçar a sua presença na Austrália, Canadá e México por meio do desenvolvimento do marketing e comercialização de produtos atuais e futuros. Em 2008 adquiriu Valeant Coria e expandiu a sua carteira com 17 produtos dermatológicos. Todas estas ações apresentaram resultados no valor da empresa que de janeiro de 2008 a janeiro de 2009 cresceu 58\% (MSN, 2009).

\subsection{Receita até US\$ 100 milhões (Pequeno porte; tipos variados)}

A categoria de empresas com faturamento anual de até US\$ 100 milhões apresentou grande variância na evolução de valor, que oscila de -83\% a 538\%, conforme a tabela 8.

Tabela 8 - Receita e valor em US\$ milhões de empresas com receita de até 100 milhões US\$/ano em 2007

\begin{tabular}{|c|c|c|c|c|c|c|c|c|c|c|}
\hline \multirow[t]{2}{*}{ Empresas } & \multicolumn{4}{|c|}{ Receita média anual no Biênio } & \multirow{2}{*}{$\begin{array}{l}\text { Var. \% } \\
\text { Biênios }\end{array}$} & \multicolumn{4}{|c|}{ Valor de mercado médio anual no biênio } & \multirow{2}{*}{$\begin{array}{l}\text { Var. \% } \\
\text { Biênios }\end{array}$} \\
\hline & $1998 / 99$ & $\%$ & $2006 / 07$ & $\%$ & & 1998/99 & $\%$ & $2006 / 07$ & $\%$ & \\
\hline Biotime 4 & 0,7 & $\overline{0}$ & 1,1 & $\overline{0}$ & 47 & 130,4 & 10 & 22,0 & 1 & -83 \\
\hline Cellegy 4 & 0,9 & 1 & 7,5 & 3 & 795 & 61,6 & 5 & 21,2 & 1 & -66 \\
\hline Oscient Pharma ${ }^{1}$ & 25,2 & 16 & 63,1 & 25 & 150 & 435,0 & 32 & 291,1 & 17 & -33 \\
\hline Cadus 4 & 9,3 & 6 & 0,1 & 0 & -99 & 18,5 & 1 & 22,8 & 1 & 23 \\
\hline Savient 4 & 76,0 & 48 & 30,6 & 12 & -60 & 585,7 & 43 & 909,9 & 53 & 55 \\
\hline Alpha 4 & 8,4 & 5 & 14,3 & 6 & 71 & 6,2 & 0 & 11,5 & 1 & 84 \\
\hline Anika & 13,60 & 9 & 28,9 & 11 & 113 & 60,8 & 4 & 153,1 & 9 & 152 \\
\hline Depomed $^{2}$ & 0,5 & 0 & 37,6 & 15 & 8438 & 45,6 & 3 & 150,5 & 9 & 230 \\
\hline Hi-Tech ${ }^{3}$ & 22,8 & 15 & 68,5 & 27 & 200 & 20,3 & 1 & 129,6 & 8 & 538 \\
\hline Valor Total & 157,3 & 100 & 251,4 & 100 & 60 & $1.364,1$ & 100 & $1.711,6$ & $\overline{100}$ & 25 \\
\hline
\end{tabular}

Fonte: MSN Money (2008) e Annual Report das empresas

(1) Empresas multiespecialistas; (2) Empresas de biofármacos; (3) Empresas de genéricos; (4)Empresas de biotecnologia

A empresa melhor avaliada foi a Hi-Tech, uma empresa fundada em abril de 1982 no estado de Delaware, e concentra-se na produção de genéricos, produtos de consumo e produtos alimentícios. Nos produtos farmacêuticos ela tem a divisão de produtos com venda livre com marcas próprias, uma linha de prescrição com marcas próprias e a linha de genéricos. As áreas terapêuticas nas quais a empresa atua são: asma, dermatologia, alergias, gastroenterologia, neurologia, higiene bucal entre outras. A empresa tem aumentado os seus esforços em produtos de marca com prescrição por meio de aquisições realizadas a partir de 2004 visando melhorar as margens de lucro por meio de produtos protegidos por patentes. Entretanto, no ano fiscal encerrado em abril de 2007, as vendas de medicamentos genéricos ainda representavam $78 \%$ do total das vendas, as vendas de produtos de saúde e linha de 
produtos OTC representaram 18\% das vendas totais, e as vendas de produtos de marca apenas $4 \%$ do total faturado. A empresa vem promovendo uma série de alianças visando viabilizar rapidamente sua estratégica de aumento de produtos com marca (HI-TECH, 2008).

A empresa que teve a segunda melhor evolução nesta categoria foi a Depomed, uma empresa dedicada à descoberta de novas moléculas para as grandes empresas e aos sistemas que levam a droga até o seu local de ação, a sua principal área de atuação é o diabetes e o sistema nervoso central, e destaca-se com um grande potencial de desenvolvimento no tratamento do mal de Parkinson e demência senil. A estratégia da Depomed é desempenhar um papel ativo na comercialização de seus produtos e desenvolver formulações de característica únicas para drogas orais orientadas para grandes contingentes de doentes. Neste sentido, a empresa trabalha com independência, bem como em parceria com empresas que compartilham essa meta, e efetuou vários acordos nos últimos anos, sendo que os mais importantes foram com a BMS e com a Avents. A terceira empresa com maior valorização foi a Anika, que se destaca com produtos revolucionários para o tratamento de artrites e uso dermatológico e oftalmológico. Entretanto o seu grande valor de mercado é atribuído ao Acido Hyalurônico que serve para várias aplicações, como o desenvolvimento de géis e membranas celulares. As aplicações potenciais da Anika visam explorar, no futuro, soluções injetáveis ou géis que podem ser combinados com outros compostos ou entidades, tais como células, fatores de crescimento e de genes. Além disso, a empresa está focada no reforço e ampliação das linhas de produtos por meio de novas formulações e outras extensões de linha. Suas principais parcerias comerciais são com a Bausch \& Lomb e com a Staar Surgical.

A BioTime Inc., foi a empresa com o pior desempenho de valor de mercado. Ela concentra-se em atividades no domínio da investigação e do desenvolvimento de soluções sintéticas para o aumento do volume sanguíneo, substituição do sangue durante cirurgias com baixíssimas temperaturas (hipotermia), e solução de preservação de órgãos destinados ao transplante. A despeito de uma série de parcerias para a distribuição e desenvolvimento de produtos, a frustração das expectativas comerciais após os lançamentos corroeu o valor que a empresa acumulou no período de pré lançamento com base em expectativas favoráveis.

\section{CONSIDERAÇÕES FINAIS}

A análise dos 47 laboratórios amostrados evidenciou que a despeito um crescimento de $92 \%$ na receita do conjunto de empresas, o valor de mercado cresceu apenas $13 \%$ entre os biênios 2006/07 e 1998/99. Como resultado, o coeficiente médio de valor sobre receita, que é um importante indicador de qualidade dos modelos de negócios, caiu de 6,5 vezes para 3,9 vezes. Consistentemente com a abordagem da migração de valor da revisão bibliográfica, observa-se que o valor migrou das empresas de porte maior para as empresas de porte menor. Como reflexo, as empresas com faturamento acima de US\$12 bilhões tiveram sua participação no valor total das empresas amostradas reduzida de 93,4\%, em 1998/99, para $77,2 \%$, em 2006/07. Por outro lado, os laboratórios de menor porte, com receita de até US\$12 bilhões tiveram um aumento de participação no valor de mercado de 6,6\% para 22,8\%.

A migração de valor dentro da indústria farmacêutica pode ser compreendida melhor quando classificamos as empresas em função de suas especiaidades. Os tradicionais laboratórios de grande porte, classificados como multiespecialistas, representados na amostra 


\section{MIGRAÇÃO DE VALOR NA INDÚSTRIA FARMACÊUTICA ${ }^{1}$}

por 12 empresas com receita média de US\$ 28 bilhões, tiveram uma perda de valor de 10\% nos nove anos considerados, enquanto os laboratórios mais especializados, e com receita média de apenas US $\$ 1,9$ bilhão, tiveram um aumento de valor de $228 \%$, ou um crescimento de valor 3,6 vezes maior. Este movimento também se reflete no coeficiente de valor sobre receita, que no caso dos 35 laboratórios menores é de 6,3, ou quase o dobro que o coeficiente de 3,3 dos grandes laboratórios multiespecialistas. Entre as empresas que mais têm atraído os investimentos dos acionistas estão os laboratórios especializados em biotecnologia e biofármacos, que diferentemente dos laboratórios tradicionais que produzem os fármacos sintetizados quimicamente, criam medicamentos com base em processos biológicos. Estes laboratórios, por serem menores e mais flexíveis, encontram-se na fronteira do conhecimento e além de produzirem remédios mais rentáveis nos dias atuais criam mais valor para os acionistas por produzirem melhores expectativas de resultados futuros. A participação destas duas especialidades no valor total das empresas pesquisadas triplicou de 9,1\%, em 1998/99, para 27,7\%, em 2006/07.

A análise dos investimentos em P\&D nas 47 empresas amostradas reforça o fato de que a manutenção na liderança do segmento farmacêutico e do posicionamento na fronteira dos novos conhecimentos exige foco, especialização e dispendiosos esforços por meio do desenvolvimento de moléculas, processos de produção e produtos com proteção de patentes, que garante alto retorno comercial. Observou-se que, consistententemente com a própria tendência das vendas no período analisado, o crescimento de investimento em P\&D nas empresas de biotecnologia e biofármacos, de $610 \%$, foi muito maior que nas empresas multiespecialistas, de $72 \%$, refletindo-se na maior capacidade de criação de valor destas empresas. Enquanto os grandes laboratórios investem cerca de 20\% da receita em P\&D, os laboratórios especializados e pequenos investem cerca de 30\%, chegando a alguns casos a $65 \%$ da receita.

Quando os laboratórios são classificados em cinco faixas de receita e a análise é replicada, observa-se um comportamento recursivo de migração de valor no sentido das empresas menores, mais focadas, com investimentos proporcionalmente maiores em $\mathrm{P} \& \mathrm{D}$, e que, por consequência, têm os portfólios de pipelines e produtos mais promissores em termos de margens de lucro. Enfim, a pesquisa realizada na indústria farmacêutica, na qual os ativos intangíveis historicamente são importante fator de competitividade, evidencia que nos últimos dez anos tem havido um claro e intenso processo de migração de valor - ou investimentos dos acionistas - entre empresas. $\mathrm{O}$ valor vem migrando dos grandes laboratórios, que tradicionalmente dominam a indústria, para os pequenos laboratórios, caracterizados por modelos de negócio mais focados em termos de áreas terapêuticas, que conseguem concentrar mais esforços e recursos em pesquisa e desenvolvimento, e por consequência são mais competitivos e criam melhores expectativas de resultados para os acionistas.

\section{REFERENNCIAS}

ABBOTT. Annual report 10K form, Washington DC, 2008, Investor Relations. Disponível em: <http://www.abbottinvestor.com/phoenix.zhtml?c=94004 \&p =irol-sec $>$. Acesso em: 25 abr. 2008. 
ANDRADE, Mônica Viegas.; LISBOA, Marcos de Barros. Externalidades difusas: uma aplicação para o caso da saúde. [s.l.]: São Paulo: EPGE/FGV, 2000.

AMGEN. Annual report 10K form, Washington DC, 2007. Investor Relations, Sec fillings, annual fillings. Disponível em: $<$ http://investors.amgen.com/phoenix. zhtml?c=61656\&p= irol-sec $>$. Acesso em: 25 abr. 2008.

AVERSARI MARTINS, Vinícius. Contribuição à avaliação do goodwill: depósitos estáveis, um ativo intangível. 154 f. Dissertação (Mestrado em Administração) - FEA/USP. São Paulo, 2002.

BOULTON, R. et al. Decifrando o código de valor. Rio de Janeiro: Campus, 2001.

BUSINESS INSIGHT - The Blockbuster Drug Outlook. Londres: Charles House, 2007.

CAMBREX. Annual report 10K form, Washington DC, 2008. Investor Relations, Sec documents, annual fillings. Disponível em: $<$ http://ir.cambrex.com/phoenix.zhtml $>$. Acesso em: 25 abr. 2008.

CELGENE. Annual report 10K form, Washington DC, 2008. Investor Relations, Sec

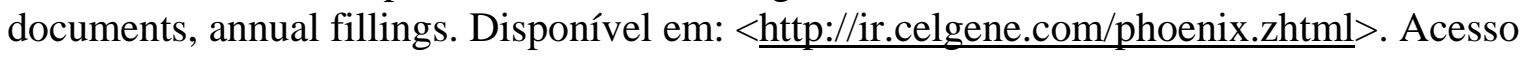
em: 25 abr. 2008.

COPELAND, T.; KOLLER, T.; MURRIN, J. Avaliação de empresas "Valuation”. Calculando e gerenciando o valor das empresas. São Paulo: Makron Books, 2002.

CUBIST. Annual report 10K form, Washington DC, 2008. Investor Relations. Disponível em: <http://www.cubist.com/investor_relations/sec.php>. Acesso em: 04 fev. 2009.

ELI LILLY. Annual report 10K form, Washington DC, 2008. Investor Relations. Disponível em: < http://investor.lilly.com/edgar.cfm>. Acesso em: 23 abr. 2008.

FAGAN, P. L. As gigantes farmacêuticas: prontas para o século XXI? Boston: Harvard Business School, 1998.

GENENTECH. Annual report 10K form, Washington DC, 2008. Investor Relations, Sec fillings, annual fillings. Disponível em: <http://www.gene.com/gene/ir/sec filings/list. do? method=list>. Acesso em: 23 abr. 2008.

GSK. Annual review, England Walles, 2008, Investor Annual Review. Disponível em: $<$ http://www.gsk.com/investors/reps07/annual-review-2007/index.html > . Acesso em: 23 abr. 2008.

JONHSON \& JONHSON. Annual report 10K form, Washington DC, 2008. Investor Relations, Sec fillings, annual fillings. Disponível em: $<\underline{\text { http://www.investor.jnj.com/ governan- }}$ ce/sec-filings.cfm>. Acesso em: 25 abr. 2008.

HITT, Michael.; et al. Administração estratégica: competitividade e globalização. São Paulo: Pioneira Thomson Learning, 2005. 
HI-TECH. Annual report 10K form, Washington DC, 2008. Investor Relations, Sec fillings, annual fillings. Disponível em: <http://www.techne-corp.com/financial.asp>. Acesso em: 23 abr. 2008.

IBGE. Pesquisa Industrial - Empresa 2005. Disponível em: <http://www.ibge.gov.br/home/ estatistica/economia/industria/pia/empresas/defaultempresa2005.shtm>. Acesso em: 20 abr. 2008.

IUDÍCIBUS, Sérgio de. Teoria da contabilidade. São Paulo: Atlas, 2000.

IMS. IMS Health Global Sales and Prescription Information. Disponível em: $<$ http://www.imshealth.com/deployedfiles/imshealth/Global/Content/StaticFile/Top_LineData /Top10GlobalProducts.pdf $>$. Acesso em: 28 abr. 2008.

KAYO, Eduardo Kazuo. A estrutura de capital e o risco das empresas tangível e intangível-intensivas: uma contribuição ao estudo da valoração das empresas. $178 \mathrm{f}$. Tese (Doutorado em Administração) - FEA/USP. São Paulo, 2002.

LEV, Baruch. Intangibles: management and reporting. Washington: Brookings, 2001.

LISBOA, Marcos B.; MOREIRA, Humberto. On capitation contracts and endogenous altruism: the managed care. Rio de Janeiro, 2000.

MILLENIUM. Annual report 10K form, Washington DC, 2008. Investor Relations. Disponível em: <http://www.mlnm.com/about/index.asp>. Acesso em: 25 abr. 2008.

MSN Money, CADUS. Annual report 10K form, Washington DC, 2007. Investor Relations. Disponível em: <http://moneycentral.msn.com/investor/sec/filing.asp>. Acesso em: 25 abr. 2008.

MSN Money, Techne. Annual report 10K form, Washington DC, 2007. Investor Relations, Sec fillings,annual fillings. Disponível em: <http://moneycentral.msn.com/investor/ sec/filing.asp>. Acesso em: 25 abr. 2008.

MSN Money. Investing Stocks. Disponível em: $<\underline{\text { http://moneycentral.msn.com/investor/ }}$ common/findsymbol.asp>. Acesso em: 25 abr. 2008.

PFIZER. Annual report 10K form, Washington DC, 2008. Investor Relations, Sec fillings,

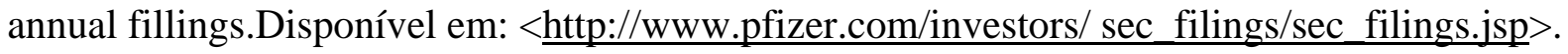
Acesso em: 25 abr. 2008.

RETAIL DRUG MONITOR. Disponível em: < $\underline{w w w . i m s h e a l t h . c o m>. ~ A c e s s o ~ e m: ~} 30$ dez. 2007.

ROCHE, Roche leads off in 2005 with impressive first quarter - pharmaceutical sales grow three times as fast as the global market. Disponível em: <http://www.roche.com/home/ service/ service-search/service-search-results.htm?qt=Tamiflu>. Acesso em: 20 abr. 2008.

RUPPRECHT, C.; Peter, G.; Rose, T. A model-driven approach for contextspecific individualization of process models. In: Wirtschaftsinformatik, v. 41, n. 3, p. 226-37, 1999. 
SLYWOTZKY, A. Migração de valor: como se antecipar ao futuro e vencer a concorrência. Rio de Janeiro: Campus, 1997.

VALEANT. Annual report 10K form, Washington DC, 2008. Investor Relations, Sec fillings, annualfillings Disponivel em: <http://phx.corporateir.net/phoenix.zhtml?c=119269\&p=irolsec >. Acesso em: 04 fev. 2009.

YAHOO Finance. Investing - Sector Healthcare. Disponível em:

<http://biz.yahoo.com/p/510conameu.html>. Acesso em: 20 abr. 2008. 